\title{
Studies on Interaction between Silica Gel and Polymer Blend by Inverse Gas Chromatography
}

\author{
Yoshimasa Murakami, Ryosuke Enoki, Yoshiro Ogoma, \\ and Yoshiyuki Kondo \\ Department of Functional Polymer Science, Faculty of Textile Science and Technology, \\ Shinshu University, Ueda, Nagano 386-8567, Japan
}

(Received December 22, 1997)

\begin{abstract}
Inverse gas chromatography of columns prepared with polymer blends of poly(ethylene oxide) and poly(methyl methacrylate) in the presence of a pulverized porous inorganic material of silica gel was carried out. From the analysis of subtle changes in the retention diagrams, information on interaction between silica gel and the blends was obtained even in the composition where the transition behavior of the blends is greatly changed by thermal treatment.

KEY WORDS Inverse Gas Chromatography / Polymer Blend / Poly(ethylene oxide) / Poly(methyl methacrylate) / Silica Gel / Compatibility / Transition Behavior / Thermal Treatment /
\end{abstract}

Inverse gas chromatography (IGC) is a simple and useful technique to investigate the physical properties of polymers such as glass transition temperature $\left(T_{\mathrm{g}}\right)$ or melting temperature $\left(T_{\mathrm{m}}\right)$ of a polymer. ${ }^{1}$ This technique has been widely used to determine thermodynamic quantities for polymers such as solubility parameters. ${ }^{2,3}$ In recent years IGC has also been utilized for polymer surface characterization. ${ }^{4-8} \mathrm{We}$ applied IGC to the evaluation of the morphological change in hydrophilichydrophobic polymer systems such as polymer blends of poly(ethylene oxide) (PEO) and polystyrene (PS), ${ }^{9}$ of poly(acrylic acid) and PS, ${ }^{10}$ of PEO and poly(methyl methacrylate) (PMMA), ${ }^{11}$ and triblock copolymers of PEO and PMMA ${ }^{12}$ prepared by anionic polymerization. ${ }^{13-15}$ Further, we have succeeded in applying IGC technique to the study on interaction between inorganic materials and polymer. ${ }^{16,17}$ Inorganics-polymer interaction is a most interesting subject and many studies have been made by various methods. ${ }^{18-20}$

In a previous paper, we clarified the transition phenomena in PEO/PMMA blends of various compositions by means of IGC. ${ }^{11}$ In compositions below $c a$. $15 \mathrm{wt} \%$ PEO, the transition behavior of the blends was mainly dominated by the PMMA component. Above ca. $45 \mathrm{wt} \%$ PEO, PEO domains were segregated in the homogeneous polymer matrix and spread out with increase in PEO content. In both regions of composition, fundamental transition behavior of the blends did not change by thermal treatment. In $c a$. $15-25 \mathrm{wt} \%$ PEO, transition behavior was greatly changed by thermal treatment. This composition range corresponded to a critical state of above-mentioned two states. In the previous study, we investigated the effect of the addition of silica gel to the PEO/PMMA blends of 5 and $50 \mathrm{wt} \% \mathrm{PEO}$, in which fundamental transition phenomena were unchanged by thermal treatment. ${ }^{17}$ Information on interaction between the blends and silica gel was obtained from changes in the retention diagrams of IGC, i.e., silica gel incorporated both PEO and PMMA into its pores and the ability of incorporation of PEO into the pores of silica gel was superior to that of PMMA. ${ }^{17}$ To promote IGC technique to one of useful tools for morphological study of multicomponent poly- mer systems, however, it is of great importance to know whether such information is obtainable even when the blends are morphologically changed by thermal treatment.

In this study, IGC measurements of columns prepared with both PEO/PMMA blends (15-40 wt \% PEO) and silica gel were carried out. This paper presents the information on interaction between silica gel and the blend before and after thermal treatment.

\section{EXPERIMENTAL}

\section{Materials}

PMMA was prepared by radical polymerization of methyl methacrylate in benzene at $60^{\circ} \mathrm{C}$ initiated with $\alpha, \alpha^{\prime}$-azobis(isobutyronitrile) (AIBN). Both PEO (Nacalai Chemical's PEO $\left.\$ 6000, M_{n}=8500\right)$ and PMMA $\left(M_{n}=\right.$ 46800) were freeze-dried from respective benzene solutions before use. Silica gel (Merck's silica gel 60, BET surface area $537 \mathrm{~m}^{2} \mathrm{~g}^{-1}$ ) was pulverized by dry-grinding in agate mortar for $1 \mathrm{~h}$. Chromosorb P AW-DMCS $60-80$ mesh (Shimadzu Co., BET surface area $3 \mathrm{~m}^{2} \mathrm{~g}^{-1}$ ), a good solid support for IGC measurements, ${ }^{21}$ was used as a support for the polymer. $n$-Nonane was used as received.

\section{Columns}

The columns prepared are summarized in Table I. A certain amount of pulverized silica gel was dispersed in a benzene solution $(2.5 \mathrm{w} / \mathrm{v} \%)$ of PEO/PMMA blend by stirring sufficiently, and to this a prescribed amount of Chromosorb was added. The benzene was allowed to evaporate at ambient temperature by gentle and continuous stirring of the solution followed by drying at $45^{\circ} \mathrm{C}$ under slightly reduced pressure. A weighed amount of Chromosorb prepared in this manner was tightly packed into a $1.5 \mathrm{~m} \times 3 \mathrm{~mm}$ internal diameter stainlesssteel column. The column was dried for $5 \mathrm{~h}$ at $45^{\circ} \mathrm{C}$ under a constant stream of helium.

\section{Measurements}

Gas chromatograms were recorded on a Shimadzu GC-8A equipped with a thermal conductivity detector, 
Table I. Column specifications

\begin{tabular}{|c|c|c|c|}
\hline \multirow{2}{*}{$\begin{array}{l}\text { Column } \\
\text { No. }\end{array}$} & $\begin{array}{l}\text { PEO content } \\
\text { in the blend }\end{array}$ & $\begin{array}{l}\text { Polymer } \\
\text { loading }\end{array}$ & $\begin{array}{l}\text { Silica gel } \\
\text { loading }^{b}\end{array}$ \\
\hline & $\mathrm{wt} \%$ & $w t \%$ & $w t \%$ \\
\hline 1 & $100^{\mathrm{c}}$ & 9.8 & 0 \\
\hline 2 & $0^{\mathrm{d}}$ & 9.7 & 0 \\
\hline 3 & 15 & 9.6 & 0 \\
\hline 4 & 20 & 9.7 & 0 \\
\hline 5 & 25 & 9.8 & 0 \\
\hline 6 & 35 & 9.7 & 0 \\
\hline 7 & 40 & 9.7 & 0 \\
\hline 8 & 15 & 9.9 & 0.5 \\
\hline 9 & 15 & 9.6 & 3.8 \\
\hline 10 & 20 & 9.9 & 0.5 \\
\hline 11 & 20 & 9.6 & 3.8 \\
\hline 12 & 25 & 9.9 & 0.5 \\
\hline 13 & 25 & 9.6 & 3.8 \\
\hline 14 & 35 & 9.9 & 0.5 \\
\hline 15 & 35 & 9.6 & 3.8 \\
\hline 16 & 40 & 10.0 & 0.5 \\
\hline 17 & 40 & 9.8 & 3.8 \\
\hline
\end{tabular}

${ }^{a}$ Polymer $(\mathrm{g}) /[$ Polymer $(\mathrm{g})+$ Chromosorb $(\mathrm{g})+$ Silica gel $(\mathrm{g})] \times 100$ ${ }^{b}$ Silica gel $(\mathrm{g}) /[$ Polymer $(\mathrm{g})+$ Chromosorb $(\mathrm{g})+$ Silica gel $(\mathrm{g})] \times 100$. ${ }^{\mathrm{c}}$ Only PEO was loaded. ${ }^{\mathrm{d}}$ Only PMMA was loaded.

with helium as the carrier gas, $n$-nonane as the solute, and air as the noninteracting marker. The method of IGC measurement has been described in previous papers. ${ }^{9,10,12}$ The gas chromatographic measurement was carried out by increasing the column temperature $T(\mathrm{~K})$. The specific retention volume $V_{\mathrm{g}}\left(\mathrm{mlg}^{-1}\right)$ was calculated from the equation $V_{\mathrm{g}}=V_{\mathrm{N}} / w . V_{\mathrm{N}}(\mathrm{ml})$ is the net retention volume of the solute from the air peak and $w(\mathrm{~g})$ is the loaded polymer weight in the column. The retention diagram (RD) was obtained by plotting $\log V_{\mathrm{g}}$ vs. $10^{3} / T$. Several days after the first measurement on a freshly packed column, the second measurement was carried out to investigate the influence of the thermal treatment on the surface feature of the polymer. The BET surface area of silica gel was measured on a Shibata SA-1000 by one-point $\mathrm{N}_{2}$-adsorption method at liquid nitrogen temperature.

\section{RESULTS AND DISCUSSION}

Figure 1 shows the retention diagrams (RDs) of the first measurement (RDs-1st) of the columns No. 1 and 2 together with RDs of the second measurement (RDs2nd). In a Z-shaped curve, the temperature of the first deviation from linearity corresponds to the transition temperature of the polymer. ${ }^{1}$ This temperature remains unchanged after thermal treatment. As can be seen from Figure 1 , the $T_{\mathrm{m}}$ of PEO and the $T_{\mathrm{g}}$ of PMMA were about 62 and $115^{\circ} \mathrm{C}$, respectively. It should be noted that the value of $\log V_{\mathrm{g}}$ in the RD of PEO at a certain temperature is fairly larger than that in the $\mathrm{RD}$ of PMMA. The RD-2nd reflects the thermally-treated phase structure of the polymer. The retention mechanism was reported previously. $1,10,11,21$ In brief, the result that the RD-2nd is not so different from the RD-1st is a characteristic of PEO. The result that the value of $\log$ $V_{\mathrm{g}}$ in $\mathrm{RD}-2 \mathrm{nd}$ is smaller than that in the RD-1st (downward shift of RD) is a characteristic of PMMA.

RDs of the third measurements were the same as the

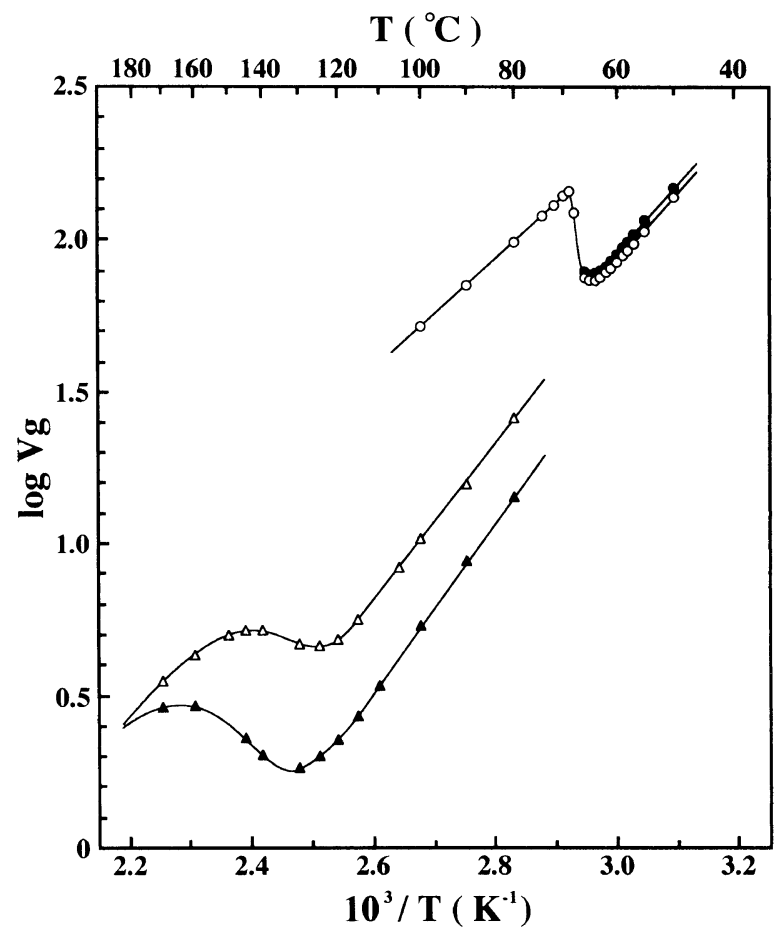

Figure 1. Retention diagrams of PEO and PMMA: $(O)$ column No. 1 (PEO, first measurement); (O) No. 1 (second); $(\triangle)$ No. 2 (PMMA, first); ( $\mathbf{\Delta})$ No. 2 (second).

respective RDs-2nd. Therefore, it is not necessary to take into account the results of the third measurements to discuss the effects of thermal treatment on phase structure of the polymer.

Figures 2-5 show the RDs of columns No. 3-6 $(15-35 \mathrm{wt} \%$ PEO) prepared without silica gel. In the RDs of $15 \mathrm{wt} \%$ PEO, only slight bendings of the slope were observed at about $60^{\circ} \mathrm{C}$ and $110^{\circ} \mathrm{C}$ and a $\mathrm{Z}$-shaped curve did not appear in the RD-1st, whereas a Z-shaped curve was clearly observed at around $80^{\circ} \mathrm{C}$ in the RD2nd. In $15 \mathrm{wt} \%$ PEO, therefore, the features of PMMA did not appear before thermal treatment but appeared after. In the RDs of $20 \mathrm{wt} \%$ PEO was seen similar tendency to that observed in $15 \mathrm{wt} \%$ PEO. In the RD-2nd, however, sharpness of the Z-shaped curve was weakened. In the RD-1st of $25 \mathrm{wt} \%$ PEO, a very slight bending of the slope was observed at about $60^{\circ} \mathrm{C}$. In the RD-2nd of $25 \mathrm{wt} \%$ PEO, the temperature of the bending was raised to about $70^{\circ} \mathrm{C}$ and a small downward shift of RD was yet observed, which indicates features of PMMA somewhat to appear by thermal treatment. In $35 \mathrm{wt} \%$ PEO, the RD-1st and RD-2nd were almost linear and overlapped. These results mean that the blend is a homogeneous polymer system which exhibits no transition phenomenon and the features of it are mainly governed by PEO. The RDs of $40 \mathrm{wt} \%$ PEO were completely the same as those of $35 \mathrm{wt} \%$ PEO. Detailed results are reported in a previous paper. ${ }^{11}$ The composition range of $15-25 \mathrm{wt} \%$ PEO is considered to be a critical state of the two homogeneous states, i.e., PMMA-predominant state(below ca. $15 \mathrm{wt} \%$ PEO) and PEO-predominant state(above $c a .35 \mathrm{wt} \%$ PEO). The results of IGC measurements of columns prepared with both the blends of this composition range and silica gel are described below. 
T $\left({ }^{\circ} \mathrm{C}\right)$

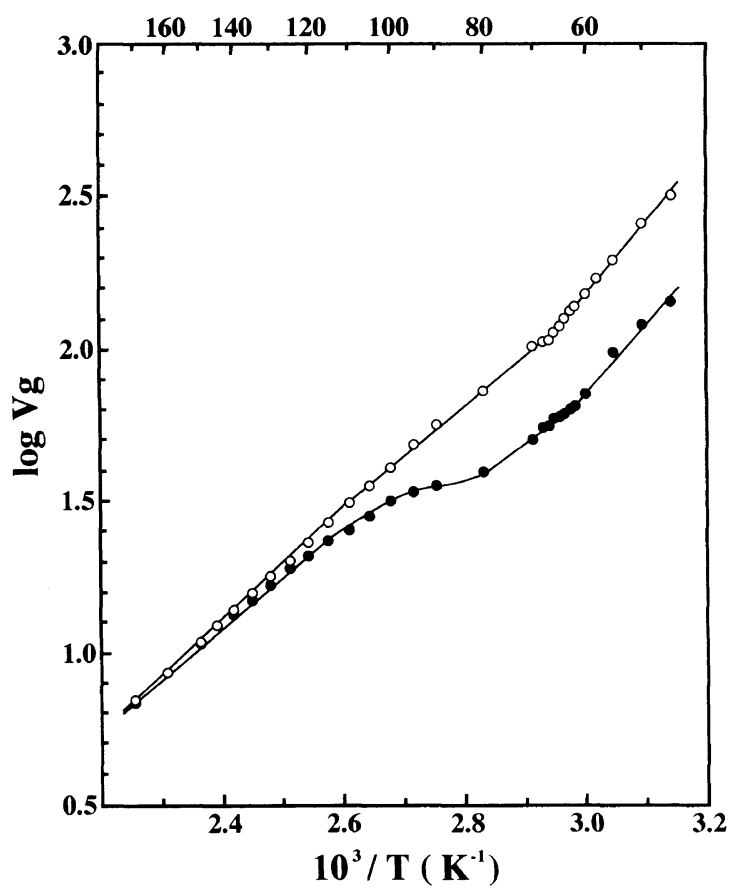

Figure 2. Retention diagrams of column No. 3 (15 wt \% PEO, without silica gel): $(\bigcirc)$ first measurement; $(\mathbf{O})$ second.

\section{$\mathbf{T}\left({ }^{\circ} \mathrm{C}\right)$}

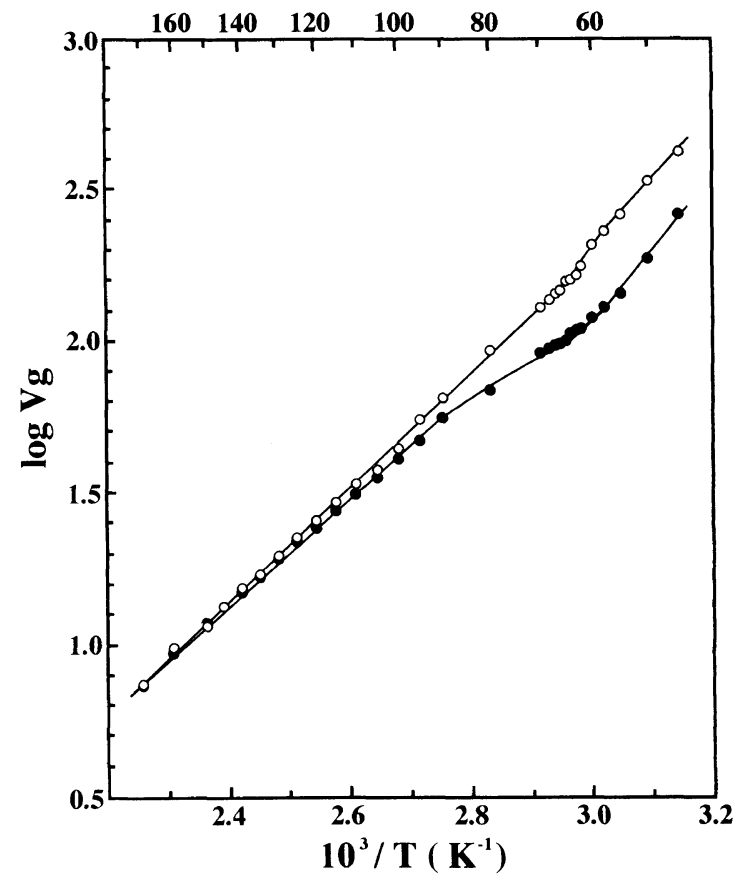

Figure 3. Retention diagrams of column No. 4 (20 wt \% PEO, without silica gel): $(\bigcirc)$ first measurement; $(\bigcirc)$ second.

To interpret the following results a model for adsorption sites for the solute of $n$-nonane on Chromosorb was proposed in previous papers ${ }^{16,17}$ and is shown in Figure 6. Three adsorption sites were considered in the retention mechanism: the surface of polymer which covers the Chromosorb surface (site A); the uncovered surface of porous inorganic material of silica gel (site B); the polymer-covered moiety of silica gel where all the pores are filled with polymer (site C). Since the

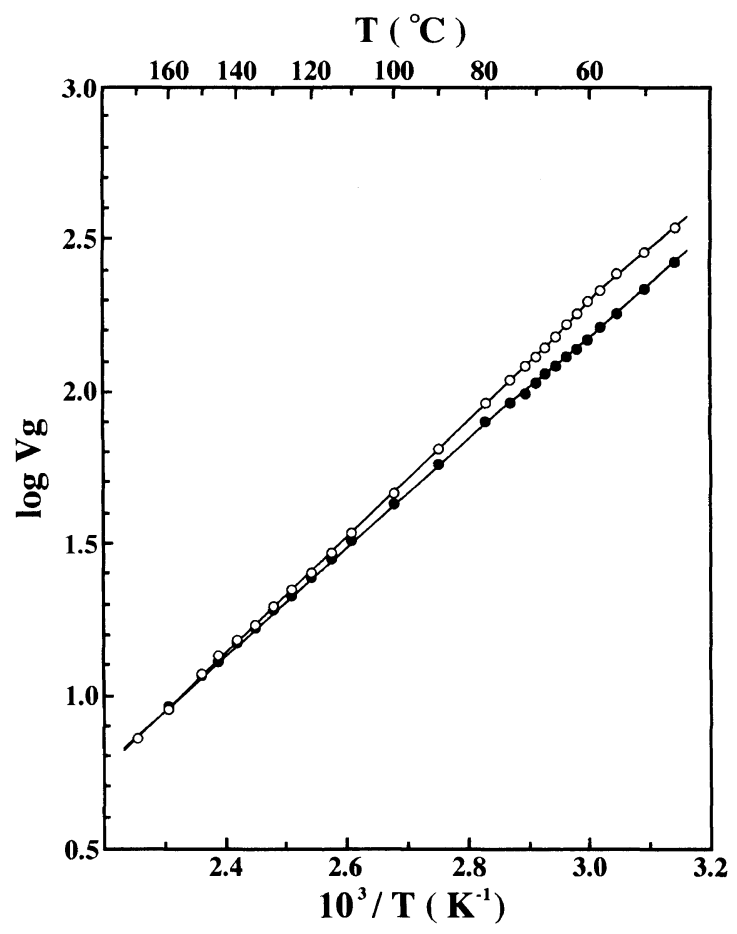

Figure 4. Retention diagrams of column No. 5(25 wt \% PEO, without silica gel): $(\bigcirc)$ first measurement; $(\bigcirc)$ second.

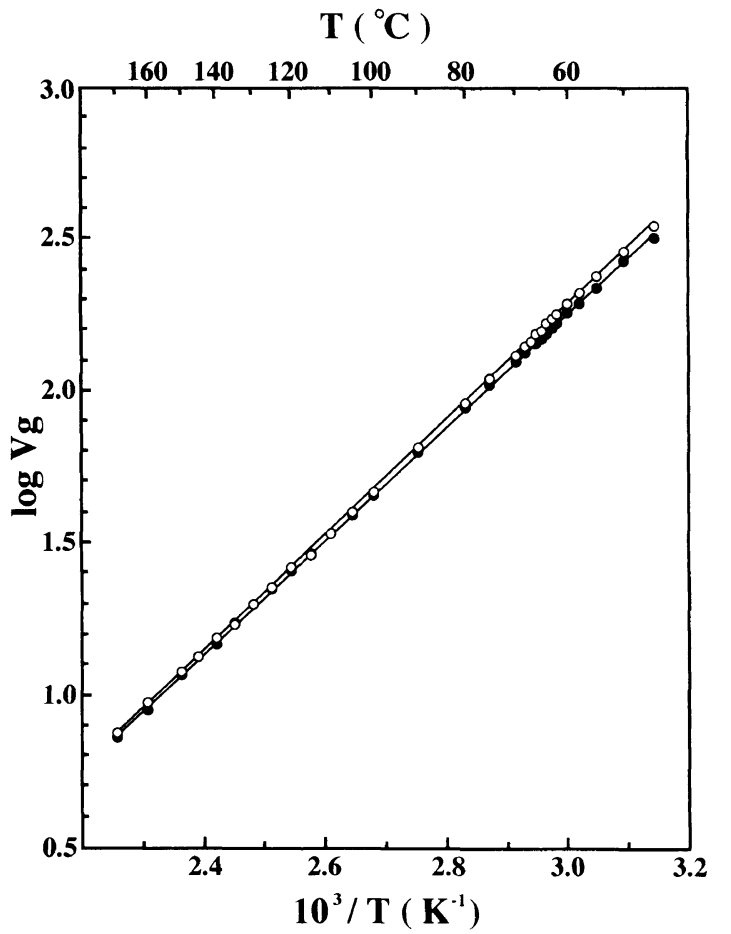

Figure 5. Retention diagrams of column No. 6(35 wt \% PEO, without silica gel): $(\bigcirc)$ first measurement; $(\bigcirc)$ second.

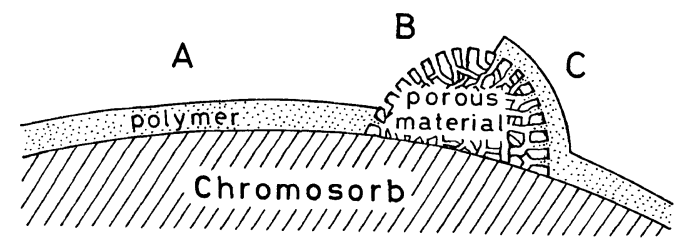

Figure 6. A model for adsorption sites for $n$-nonane. 


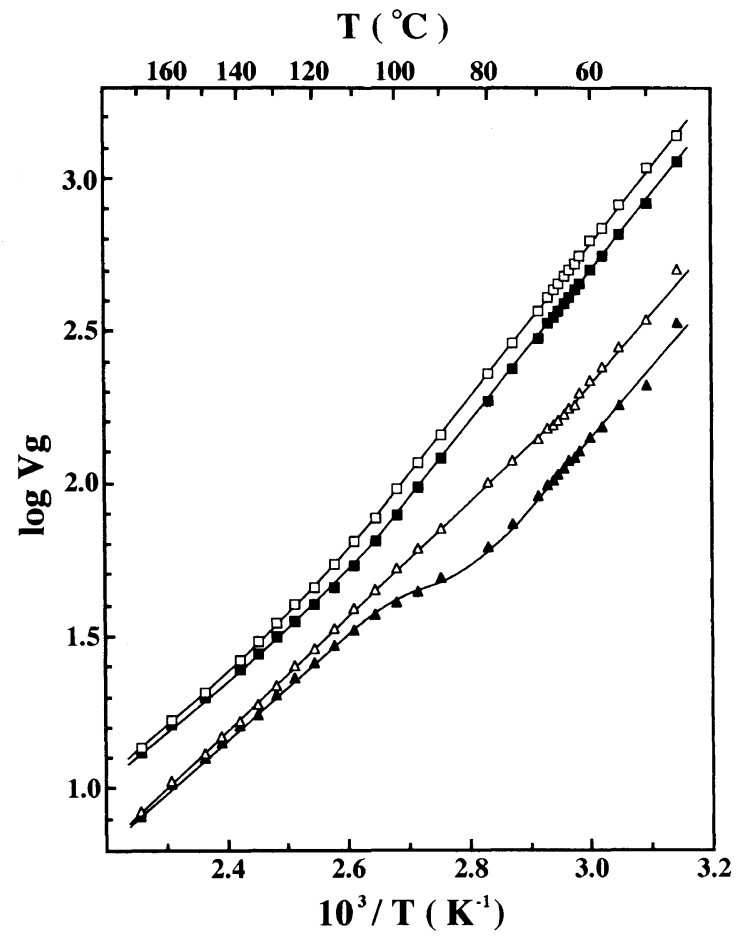

Figure 7. Retention diagrams of PEO/PMMA blends with silica gel: $(\triangle)$ column No. 8 (15 wt \% PEO, $0.5 \mathrm{wt} \%$ silica gel, first measurement);

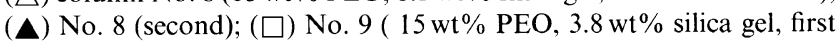
measurement); (ם) No. 9 (second).

grain size of Chromosorb was fairly larger than that of silica gel, the surface area of polymer at site A is considered to be much larger than that at site $\mathrm{C}$. The adsorption-desorption of the solute ( $n$-nonane) at site $\mathrm{A}$, therefore, mainly governs the features of retention diagrams. The adsorpiton of $n$-nonane at the surface of silica gel (site B) is much stronger than that of polymer. The existence of site $\mathrm{B}$, therefore, brings about increase in retention volume of the solute in gas chromatography, which results in upward shift of RD. A large amount of site $\mathrm{C}$ corresponds to decrease in amount of polymer at the site A, which changes fundamentally the feature of RD.

Figure 7 shows the RDs of columns No. 8 and 9 ( $15 \mathrm{wt} \%$ PEO, with silica gel). In the RD- 1 st of $0.5 \mathrm{wt} \%$ silica gel, the bending at about $60^{\circ} \mathrm{C}$ became much slighter and that at about $110^{\circ} \mathrm{C}$ disappeared. This is due to decrease in amount of PEO and PMMA at site $A$ as a result of incorporation of polymer into pores of silica gel (site $\mathrm{C}$ ). In the RD-2nd of $0.5 \mathrm{wt} \%$ silica gel, a $\mathrm{Z}$-shaped curve appeared at around $80^{\circ} \mathrm{C}$ as well as in the case of non-addition of silica gel. The addition of silica gel, therefore, does not prevent the appearance of features of PMMA by thermal treatment. The RDs of $3.8 \mathrm{wt} \%$ silica gel depicted straight lines and weak curves below and above about $105^{\circ} \mathrm{C}$, respectively. Linearity at around $60^{\circ} \mathrm{C}$, which corresponds to the $T_{\mathrm{m}}$ of $\mathrm{PEO}$, means incorporation of most of PEO into pores of silica gel. If only PEO is selectively incorporated into pores of silica gel similarly to the blend of PEO and

\footnotetext{
*1 From our unpublished results, low loading of PMMA on Chromosorb resulted in the RD of a weak curve and also in no Z-shaped curve.
}

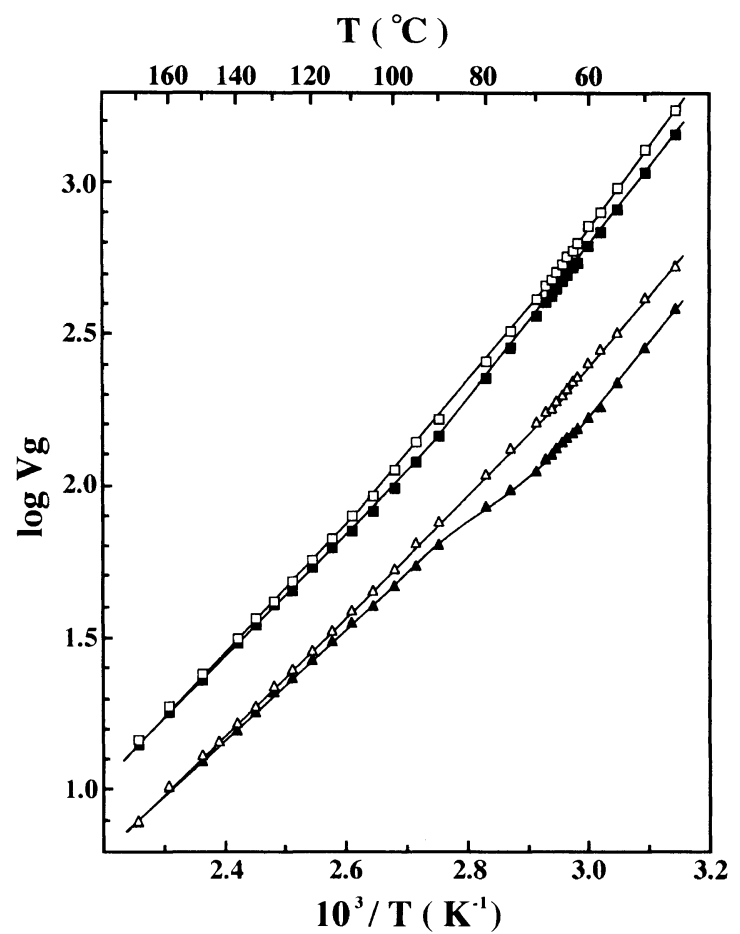

Figure 8. Retention diagrams of PEO/PMMA blends with silica gel: $(\triangle)$ column No. $10(20 \mathrm{wt} \%$ PEO, $0.5 \mathrm{wt} \%$ silica gel, first measurement); ( $\Delta)$ No. 10 (second); ( $\square$ ) No. 11 (20wt\% PEO, $3.8 \mathrm{wt} \%$ silica gel, first measurement); ( $\square$ ) No. 11 (second).

PS, ${ }^{16}$ the composition of PMMA at site A will increase more than $85 \mathrm{wt} \%$ PMMA and consequently a Z-shaped curve should appear at around $110^{\circ} \mathrm{C}$ in the RD of higher silica gel content. As can be seen from Figure 6, however, no Z-shaped curve was observable in the RDs of $3.8 \mathrm{wt} \%$ silica gel. This indicates that both PEO and PMMA were incorporated into pores of silica gel. Since the absolute amount of PMMA at site A was small, the RDs at around $105^{\circ} \mathrm{C}$ did not depict Z-shaped curves but weak curves in $3.8 \mathrm{wt} \%$ silica gel. ${ }^{* 1}$ Downward shift of RDs indicates that the transition behavior of the blend is mainly governed by PMMA. Upward shift of RDs with the increase in amount of silica gel is due to an increase in amount of site $B$.

In Figure 8 are shown the RDs of columns No. 10 and $11(20 \mathrm{wt} \%$ PEO, with silica gel). Fundamental tendency is the same as is in the case of $15 \mathrm{wt} \%$ PEO. In the RDs of $3.8 \mathrm{wt} \%$ silica gel, the shape of RDs at around $105^{\circ} \mathrm{C}$ changed from weak curves to very slight bendings. This is ascribed to a decrease in amount of PMMA in the column of $20 \mathrm{wt} \%$ PEO compared to that of $15 \mathrm{wt} \%$ PEO. Downward shift of RD-2nd, however, shows the existence of PMMA at site A.

Figure 9 depicts the RDs of columns No. 12 and 13 ( $25 \mathrm{wt} \%$ PEO, with silica gel). In the RD-1st of $25 \mathrm{wt} \%$ PEO without silica gel, a very slight bending of the slope was observable at around $60^{\circ} \mathrm{C}$, whereas the temperature shifted to about $70^{\circ} \mathrm{C}$ in the RD-1st of $25 \mathrm{wt} \%$ PEO with $0.5 \mathrm{wt} \%$ silica gel. This means the appearance of features of PMMA in the blend and suggests that the composition of PMMA component at site A increased by the addition of silica gel. In the RD-1st of $3.8 \mathrm{wt} \%$ silica gel, a slight bending of the slope emerged at around $105^{\circ} \mathrm{C}$ in addition to that at around $70^{\circ} \mathrm{C}$. These bendings became 


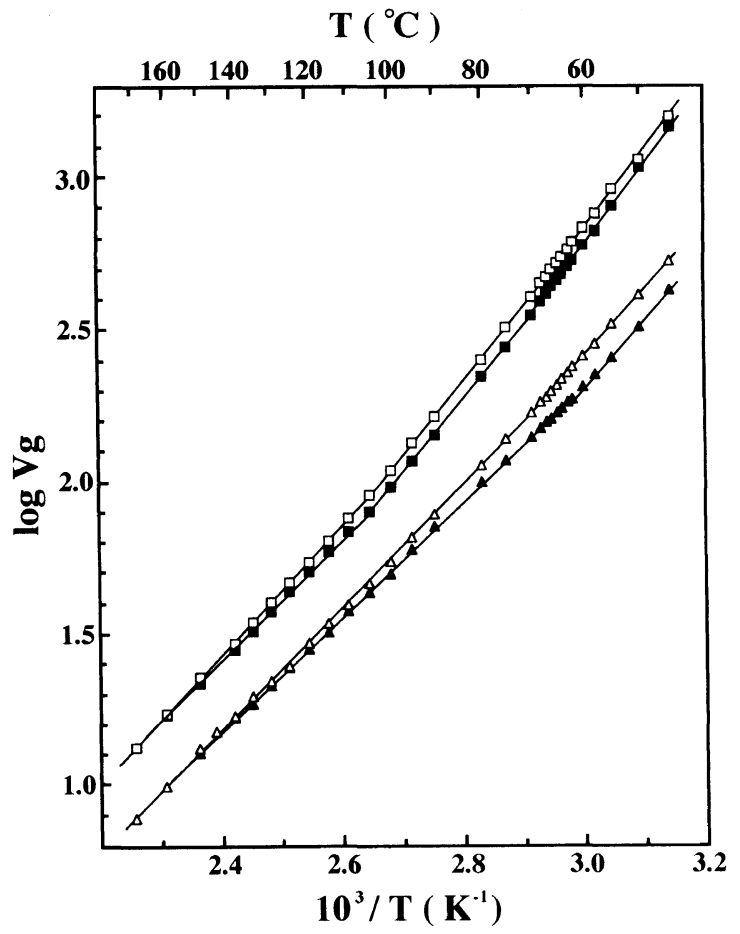

Figure 9. Retention diagrams of PEO/PMMA blends with silica gel: $(\triangle)$ column No. 12 ( $25 \mathrm{wt} \%$ PEO, $0.5 \mathrm{wt} \%$ silica gel, first measurement); (ム) No. 12 (second); ( $\square$ ) No. 13 (25 wt \% PEO, $3.8 \mathrm{wt} \%$ silica gel, first measurement); (ם) No. 13 (second).

somewhat clearer in the RD-2nd. The emergence of the bendings at around $105^{\circ} \mathrm{C}$ indicates that the features of PMMA clearly appeared at site A. If ability of incorporation of PMMA is identical with that of PEO, the composition of the blend at site $\mathrm{A}$ is constant (25 $\mathrm{wt} \% \mathrm{PEO}=75 \mathrm{wt} \%$ PMMA) and the bendings of the slope at around $70^{\circ} \mathrm{C}$ and $105^{\circ} \mathrm{C}$ in RD is expected not to be observed. However, they were observed at around respective temperatures. Therefore, it is concluded that ability of incorporation of PEO into the pores of silica gel is superior to that of PMMA. In contrast silica gel selectively incorporated PEO into the pores in the PEO/ PS blends. ${ }^{16}$

The RDs of columns No. 14 and 15 (35 wt\% PEO, with silica gel) are shown in Figure 10. In this composition without silica gel, two components are completely compatible and the transition behavior of the blend is mainly dominated by PEO component. ${ }^{11}$ As can be seen from the RDs of $0.5 \mathrm{wt} \%$ silica gel, slight bendings of the slopes were observed at around $110^{\circ} \mathrm{C}$. These appearance of the bendings are due to an increase in composition of PMMA brought by preferential incorporation of PEO into the pores of silica gel. Further, in the RDs of $3.8 \mathrm{wt} \%$ silica gel, slight bendings of the slopes were seen at around $70^{\circ} \mathrm{C}$ in addition to that appeared at around $110^{\circ} \mathrm{C}$. The RDs of $3.8 \mathrm{wt} \%$ silica gel became analogous to the RDs of the column prepared by less PEO content ( $c a .20 \mathrm{wt} \%$ PEO). These results are consistently explained on the basis of the preferential incorporation of PEO into the pores of silica gel. In the RDs of $40 \mathrm{wt} \%$ PEO (columns No. 16 and 17, with silica gel), almost the same results were obtained as were in the RDs of $35 \mathrm{wt} \%$ PEO.

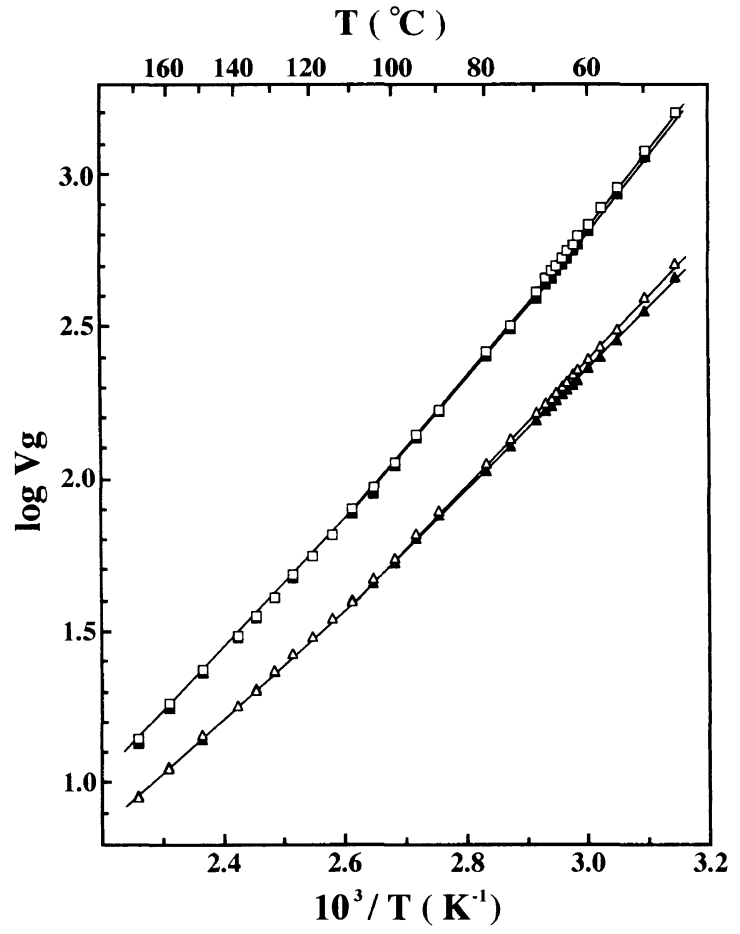

Figure 10. Retention diagrams of PEO/PMMA blends with silica gel: $(\triangle)$ column No. $14(35 \mathrm{wt} \%$ PEO, $0.5 \mathrm{wt} \%$ silica gel, first measurement); (ム) No. 14 (second); ( $\square$ ) No. 15 (35 wt \% PEO, 3.8 wt \%

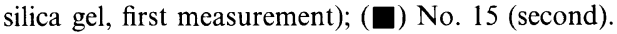

\section{CONCLUSIONS}

In PEO/PMMA blends, porous inorganic material of silica gel incorporated not only PEO but PMMA into its pores and the ability of incorporation of PEO into the pores of silica gel was superior to that of PMMA. This information has already been obtained for the blends of 5 and $50 \mathrm{wt} \%$ PEO where compatibility of both components was basically unchanged by thermal treatment. ${ }^{17}$ The same information was obtained even for the blends where the transition behavior is greatly changed by thermal treatment. As described above, IGC is a simple, sensitive and useful technique and will be widely applicable to studies of many multicomponent polymer systems. Especially, delicate change in the transition behavior by thermal treatment can be easily detected.

\section{REFERENCES}

1. J.-M. Braun and J. E. Guillet, Adv. Polym. Sci., 21, 107 (1976).

2. E. Morales and J. L. Acosta, Polym. J., 28, 127 (1996).

3. A. Voelkel, E. Andrzejewska, R. Maga, and M. Andrzejewski, Polymer, 37, 455 (1996).

4. P. G. Demertzis, K. A. Riganakos, and K. A.-Demertzi, Eur. Polym. J., 26, 137 (1990).

5. A. Etxeberria, J. M. Elorza, J. J. Iruin, C. Marco, M. A. Gomez, and J. G. Fatou, Eur. Polym. J., 29, 1483 (1993).

6. P. Mukhopadhyay and H. P. Schreiber, Macromolecules, 26, 6391 (1993).

7. P. Mukhopadhyay and H. P. Schreiber, J. Polym. Sci., Part B, Polym. Phys. Ed., 32, 1653 (1994).

8. H. Chtourou, B. Riedl, and B. V. Kokta, J. Adhesion Sci. Technol., 9, 551 (1995).

9. T. Suzuki, Y. Murakami, T. Inui, and Y. Takegami, Polym. J., 13, 1027(1981).

10. Y. Murakami, T. Inui, and Y. Takegami, Polym. J., 15, 415(1983). 
11. Y. Murakami, Polym. J., 20, 549 (1988).

12. T. Inui, Y. Murakami, T. Suzuki, O. Yamada, and Y. Takegami, Macromolecules, 17, 195 (1984)

13. T. Suzuki, Y. Murakami, Y. Tsuji, and Y. Takegami, J. Polym. Sci., Polym. Lett. Ed., 14, 675 (1976).

14. T. Suzuki, Y. Murakami, and Y. Takegami, Polym. J., 12, 183 (1980).

15. T. Suzuki, O. Yamada, Y. Murakami, Y. Takegami, and Y Watanabe, Macromolecules, 15, 223 (1982).
16. Y. Murakami, T. Inui, and Y. Takegami, Polymer, 24, 1596 (1983)

17. Y. Murakami, Polym. J., 26, 607 (1994).

18. M. P. Wenger, P. Blanas, P. J. Shuford, and D. K. Das-Gupta, Polym. Eng. Sci., 36, 2945 (1996).

19. G. Blanchet, J. Appl. Phys., 80, 4082 (1996).

20. A. Wojcik and L. Klein, Appl. Organometal. Chem., 11, 129 (1997).

21. T. Inui, Y. Murakami, T. Suzuki, and Y. Takegami, Polym. J., 14, 261 (1982). 